\title{
Discussion on Issues of Inheritance of Internet Virtual Property
}

\author{
Pengfei Ji \\ Department of Foundation, Northeast Petroleum University at Qinhuangdao, Qinhuangdao, China \\ Email: guicaitang@163.com
}

Received 20 February 2015; accepted 3 March 2015; published 6 March 2015

Copyright (C) 2015 by author and Scientific Research Publishing Inc.

This work is licensed under the Creative Commons Attribution International License (CC BY). http://creativecommons.org/licenses/by/4.0/

(c) (i) Open Access

\begin{abstract}
With the increasingly close connection between the Internet and citizens, the Internet virtual property is increasing in large amount. Although the viewpoints the parties hold about "virtual property" are different in the judicial practice, the analysis from the perspective of legal principle indicates that virtual property should be included in the legacy as "legitimate property" and legally inherited by its successor without doubt. In addition, there is a need to improve the laws and regulations on Internet user protocol and coordinate the interests of all parties.
\end{abstract}

\section{Keywords}

\section{Legacy, Virtual Property, Legal Property, Law of Inheritance, Internet User Protocol}

\section{Definition of Virtual Legacy}

Virtual property refers to all different kinds of information resources that exist depending on the cyberspace but dominated by human beings in a relatively independent way. Virtual property has a value of property despite of its digital form and covers virtual objects, like game incarnation, props, equipment, virtual currencies, etc.; virtual intangible property, like domain names, QQ accounts, etc.; and virtual collective property, such as websites, online shops, etc.

\section{Content of the Inheritance of Virtual Legacy}

The ownership of virtual property has always been a starting point and an important basis to explore the relevant various legal issues. The author believes that there are many types of virtual property that are produced or obtained in different ways, and the Internet users have different demands for them and use them in different ways, so there must be a difference in the types of the claims raised by the users: 1) The Internet users are empowered 
to use e-mail, QQ account and other user accounts as the virtual property. Actually, user account is an account stored on the server of Internet company and the Internet company has the complete ownership of it. The users need to sign an appropriate agreement with the Internet company when applying for an free or paid account and address [1], and they are then to be granted the right to use such virtual property in the agreed period of use. The users have the right not only to obtain the appropriate service but to use the virtual property by themselves, lend or even transfer the virtual property to others. 2) The Internet user should have the ownership of online game resource and virtual currencies in games. Since the users have the absolute domination over their own specific virtual characters and types and amount of their possession, they are allowed to manage the above practically and legally, for instance, they may delete, abandon or transfer the acquired virtual objects to others by trading or giving. 3) E-mail, images, data stored in e-mail box, blog or SNS social networking tool, together with music, movies, APP and others in electronic data form purchased by users from cyberspace, are closely related to the personality interests of the user and should thus be owned by the user as personal information. Certainly, the exercise of ownership of the above two kinds of virtual property should be governed by the law and Internet user protocol without affecting the nature of the rights [2].

Based on the above analysis, after the death of the Internet users, their successors are entitled to inherit the ownership or the right to use of the above different Internet virtual property except the property right exclusive to the deceased owing its close personal relation with the deceased.

\section{Legitimacy of Virtual Legacy as Legal Property}

\subsection{Legality of Way of Acquisition}

The virtual property is acquired from the Internet environment and usually regulated based on Internet user protocol made between the Internet users and Internet operators or Internet service providers. Users can obtain the ownership or the right to use of the virtual objects in the online games and communication tools including e-mail boxes, QQ numbers from specific in-game activities, or by login, trading, giving and other ways.

\subsection{Legality of the Acquired Object}

The virtual property, different from material wealth in the real world, is not included as tangible objects in the "Real Right Law", but it has the same specificity and independence as objects. Although this has not been directly acknowledged by our law, the State Administration of Taxation has issued a document requiring to levy a $20 \%$ income tax on "virtual currency transaction", which actually acknowledges virtual currency indirectly as a kind of property as stipulated in the law (tax law). Furthermore, as can be seen from many cases about virtual property adjudicated in the domestic, the courts mostly acknowledge that the Internet users have a certain rights and interests to the virtual property and the rights and interests should be protected by the law [3]. Some countries have made response to it at the legislative level, for instance, South Korea's legislation states that the characters and props in online games have the value of property independent of game operators. Oklahoma of the United States allows the courts to decide, as the case may be, who to legally inherit the unloaded digital photos, e-mails and other virtual property from the deceased if the deceased did not clearly point out how to address the virtual property in his/her lifetime.

The core of legislative spirit of the "Law of Inheritance" is to protect the legitimate rights of the successors and the deceased. There are reasons to believe that the virtual property can be included in the scope of inheritance and considered as “other legal property of citizens” as long as the virtual property owned by the Internet users complies with the legal standards.

\section{The Significance of the Inheritance of the Internet Virtual Property}

First, the inheritance of virtual property helps protect and realize the economic value of the property and promotes the rational utilization of resources. The virtual property exists in the cyberspace but its value works in the real world through exchanging with the physical money regardless of whether the law has already conferred a due status to the virtual property. The property value of such property produced or traded in virtual space can be saved if transferred to others for use by inheritance rather than deleted simply after the death of the Internet user or game player. From the microscopic point of view, this protects the rights and interests to the private property, 
and from the macroscopic point of view, this supports the rational utilization of social resources and reduces the waste of resources caused by the death of citizens.

Second, the inheritance of virtual property can encourage the Internet users to be engaged in the creation and work, promote the exploration on the productive and creative technologies and allow people to keep the value they have created and constructed in the cyberspace by inheritance, which will greatly encourage without doubt all individuals to continue to innovate, in addition, the inheritance of virtual property helps advance the development of the current virtual economy, and whether this economy will experience a rapid development greatly depends on the development of online products and the innovation on network entertainment and communication methods.

Third, the inheritance of virtual property shows not only the respect for the wishes of the deceased but the realistic demand his/her successors have for spirit and interests. The activities the Internet users have conducted in the cyberspace are an important part of their real life. From the point of the simple emotion the human beings have in common, most people hope to leave behind some property and souvenirs, even in digital form, in their lifetime to make it possible for their relatives or friends to know their thoughts and ideas and to remember them. The spiritual satisfaction may greatly exceed its material value, and such demand is guaranteed in the same way [4].

Finally, the inheritance of virtual property is the need of information dissemination between generations and has profound significance on the historical inheritance of mankind. The development of digital and information technology has turned the Internet into a "new medium" of our age, and its popularity makes it possible for each of us to act as the recorder of our own history which is an important part of "cultural heritage" available in this age, and there will be a huge regret for both the modern people and our future generations if it disappears as the user dies.

\section{The Effect of Internet User Protocol on the Inheritance of Virtual Legacy}

\subsection{The Validity of Terms of Internet User Protocol}

The virtual property exists depending on the Internet environment, so the contractual relationship between the user and Internet service provider is crucial for the acquisition and exercise of the property right, and the establishment of the contractual relationship usually relies on the contract drawn up unilaterally by the Internet service provider, namely, the Internet user protocol, which is often used as the most important basis to determined rights and obligations of the parties owing to the lack of regulations for various legal relations concerning the Internet service. The electronic contract, although saving the transaction costs and improving the transaction efficiency, limits the Internet users' freedom, what's more, the Internet service providers, also as the contract providers, tend to reduce or waive their obligations and liabilities under the contract, empower themselves some special rights (for instance, service providers can modify and terminate the contract, and the Internet users are only kept informed of it), and limit the rights content and the way to exercise the right (limit the legal relief ways available for users) and so on, which create the situation where the rights and obligations of the contracting parties are seriously unequal and affect the scope involving the inheritance of virtual property.

In regard to the provisions of Internet user protocol, we have to admit that before the Internet users accepted the Internet service, conducted Internet activities, acquired and exercised the rights and interests to the virtual property, they had indicated the willingness to be bound by the protocol at a certain way, although it may be a generalized acceptance. However, can we thus consider all terms and conditions of the protocol to be binding upon the users? At present, our country has not established the legal system to directly regulate Internet user protocol, but for format contract or electronic contract, the relevant regulations in the "Contract Law", the "Law on the Protection of the Rights and Interests of Consumers" and other laws can be used as a basis to judge the validity of the user protocol. According to Articles 39, 40, 41 in the "Contract Law" and Articles 2, 24 in the "Law on the Protection of the Rights and Interests of Consumers", the user protocol must be signed in accordance with the following strict requirements: the content of the terms must be fair; the party providing provisions shall not waive its liabilities, or enhance the other party's liabilities or exclude the other party's main rights, and they have a responsibility to draw the consumers' attention to the exceptions or limitation provisions when entering into an agreement and shall interpret the format provisions in accordance with user's requirements, etc., and any agreement or provision in violation of the above requirements shall be invalid in part. 


\subsection{The Relationship between Internet User Protocol and Protection of User's Privacy Right}

Some of the Internet service providers deny the requirements for the inheritance of virtual property from the Internet user based on another reason: the service providers who are subject to Internet user protocol have an obligation to prevent the disclosure of users' privacy to anyone in order to maintain the information security in the Internet environment. One view is that the Internet virtual property includes the personal information stored in various ways in the cyberspace (like e-mail box, social networking tool) provided by the service provider, and it may involve the privacy of the deceased. In recent years, the privacy right has been incorporated as an independent civil right into the protection scope of the "Tort Law" of our country, theoretically stating the protection of the deceased's privacy right, and in this regard, the successors and other civil parties have the obligation of inviolability. If the implementation of inheritance of virtual property violates the deceased's privacy, the law needs to make a choice from the conflicting rights value, but the question is whether there is a real conflict between the successor's inheritance right and the deceased's privacy right? In this regard, we can explain it based on a study of what is similar to the inheritance of physical legacy in the real world [5].

The Article 3 in the "Law of Inheritance" states that the legacy covers "cultural subjects, books and data of citizens", when compared with the "personal information" as virtual property, it has no difference from the virtual property in content and sensible form, and the only difference can be found in how they are stored: the former is shown in a physical form (such as the letters kept in safe deposit boxes), while the latter is the electromagnetic recording in network hard disk. If the inheritance in a physical form does not violate the privacy right, neither does the latter without doubt. Furthermore, from the perspective of the protection of privacy right, the citizens should safeguard their privacy right on their own besides depending on the legal protection. If an Internet user does not want anyone to know his/her living status in the Internet world or other privacy stored in the Internet world, the user should take protective measures on his/her own initiative in his/her lifetime (such as specifically authorizing the service provider to delete the virtual property); on the contrary, if the user fails to conduct such activities or express his/her willingness, it is allowable to presume the inheritance of the successor meets his/her true willingness under the "Law of Inheritance", and there is no concern about whether the inheritance violates his/her privacy right.

\subsection{The Obligation of Internet Service Providers for Heritage of Virtual Property}

The characteristics of the Internet virtual property determine that the legal relation of inheritance is established not only between the successor and the deceased, but involving the Internet service providers. On one hand, the unique existence and operation mode of virtual property determine that the service provider is liable not only for the negative inviolability, but for the positive custody and shall support the transfer of the virtual property for the purpose of the realization of the inheritance; on the other hand, the successor has the obligation to obtain and govern the virtual property under the legal provisions and the Internet protocol.

The inheritance involves a legal relationship and requires for universally-applicable rules and strict measures for dereliction of duty, to which the law must make appropriate response. Currently, the inheritance of virtual property has gradually come into the law of some states in the United States, including Wisconsin State, Rhode Island, which provides good legislative reference for us. The legal system to regulate the inheritance of virtual property covers the definition of the scope of legacy, the successors' qualification examination, the realization of inheritance and all other aspects of legal relation of the inheritance, meanwhile, some unprecedented issues may arise not included in the conventional Law of Inheritance owing to the special object of inheritance relationship, for instance, the way in which the Internet service provider transfers the virtual property, the value assessment and distribution of virtual property and so on. In summary, the modernization of the Law of Inheritance has a long way to go in the information and digital age.

\section{References}

[1] Mei, X.Y. and Xu, K. (2013) Theory and Legislative Problems of the Inheritance of Virtual Property. Jurists Review, 6, 26-28.

[2] Che, D. (2014) The Construction of Legal System of the Inheritance of Internet Virtual Property. Legal and Economy, 15, 87-89. 
[3] Jiang, L. (2014) Criminal Law Protection of Internet Virtual Property. Legal System and Society, 31, 44-45.

[4] Ma, Y.D. (2013) Exploration on Issues of the Inheritance of Internet Virtual Property. Studies in Law and Business, 5, 20-23.

[5] Gao, N.N., Dai, M.M. and Yao, R.J. (2014) A Brief Analysis on Issues of the Inheritance of Internet Virtual Property. Legality Vision, 12, 78-80. 